\title{
0 “Novo" Sindicalismo Brasileiro e o papel da crítica: Análise das estratégias de engrandecimento da prática sindical brasileira na década de 1980
}

\author{
Ricardo José Braga Amaral de Brito*
}

\begin{abstract}
Resumo: 0 presente trabalho visa compreender as estratégicas de engrandecimento e de mobilização de provas acerca do princípio de equivalência e de justiça empreendidos pelo sindicalismo brasileiro da década de 80 . Tal prática de sindicalismo pretendia exercer uma crítica ao modelo sindical adotado antes e depois do golpe burguês-militar de 1964. Através do ferramental teórico da escola de Sociologia da Crítica francesa, e da compreensão do desenvolvimento da teoria sociológica, será possível entender tais práticas e contribuir para o entendimento do período da ditadura, aprofundando dentro do contexto histórico as práticas exercidas para a crítica do modelo de acumulação capitalista brasileiro adotado desde os anos de 1950, mas também para compreender como o capitalismo se apropriou das críticas e possibilitou a manutenção das relações de exploração.
\end{abstract}

Palavras-chave: sindicalismo, Sociologia da Crítica, ditadura empresarial-militar, capitalismo.

\section{Introdução}

Através do ferramental teórico produzido pelo pragmatismo francês buscase analisar a evolução do movimento sindical brasileiro. Refletindo acerca das estratégias de engrandecimento (BolTANSKI, 2000) e de mobilização de provas que remetam ao princípio de equivalência e justiça (BoltansKi e CHIAPELlo, 1999; Boltanski e ThÉvenot, 1999), pretende-se analisar o surgimento do "novo" sindicalismo brasileiro no final da década de 70, prática sindical caracterizada por críticas ao modelo de sindicalismo adotado antes e depois do golpe empresarialmilitar de 1964, associando-o à intensificação das práticas corporativistas.

Para tanto, é preciso analisar o contexto histórico em que esta mudança no sindicalismo ocorreu, entendendo-a também como crítica ao sistema de acumulação capitalista compreendido entre a década de 50 até os anos 2000 que combina altos lucros e superexploração da classe trabalhadora. Contudo, o capitalismo tende a se apropriar das críticas recebidas, possibilitando a manutenção das relações de exploração e do impulso de acumulação, apresentando-se como entrave à emancipação ou melhoria de vida da classe trabalhadora (BOLTANSKI e CHIAPELLO, 1999).

\section{Novo Sindicalismo e o contexto das reivindicações}

Ao longo da Ditadura empresarial-militar, apesar da recessão econômica que tem início anterior ao golpe (1962 - 1967), a "resolução das contradições entre relações de produção e nível de desenvolvimento das forças produtivas é 'resolvida'

* Graduando em Ciências Sociais - UFRJ 
pelo aprofundamento da exploração do trabalho" (OLIVEIRA, 1972, p. 105). Duas formas que se apresentaram em interdependência marcaram o período do "Milagre econômico" (1967 - 1973): a repressão e a expansão econômica.

0 golpe de 64 consolida o modelo de acumulação capitalista implementado nos anos 50 com o Plano de Metas de Juscelino Kubitschek. Enquanto o Estado assumia uma grande dívida interna e externa de forma a garantir as condições de superacumulação do empresariado brasileiro, a reprodução do capital era intensificada pela exploração do trabalho; o uso de novas tecnologias, provenientes do investimento do capital estrangeiro, reduzindo o tempo necessário de produção e aumentando o exército industrial de reserva; e o arrocho salarial, reduzindo o real poder aquisitivo do salário e a capacidade de reprodução social do trabalhador ${ }^{1}$.

Desde o Plano de Metas que as classes trabalhadoras brasileiras são impactadas com o aumento da taxa de exploração sem aumento dos salários (com exceção dos anos de 1952 e 1953, quando João Goulart, enquanto ministro do Trabalho de Getúlio Vargas, efetiva um aumento salarial de 100\%). As classes subalternas sofreram com a transferência do ônus de combate à inflação por meio da tributação indireta, do controle salarial e dos altos gastos governamentais (que promovia subsídios e não arrecadava e nem exercia distribuição de renda).

0 Estado participou de outras formas que não o fortalecimento do empresariado por meios "puramente" (ou que assim se tentam passar) econômicos. Mas consolidou uma legislação social que reprimia a organização dos trabalhadores, que privava os sindicatos de poder de barganha, submetendo-os ao padrão de salário e reajustes do Governo (tanto urbano-industriais quanto ao setor rural, cujos sindicatos são então institucionalizados), o aumento da rotatividade do emprego e da alta exploração com o FGTS (Fundo de Garantia do Tempo de Serviço, instituído em 1966 e com a finalidade de repassar os custos da demissão do trabalhador para o Estado, retirando o ônus do patrão). Estas medidas de cunho político visavam o enfraquecimento e a desmobilização das classes trabalhadoras.

Com o golpe militar de 1964 o movimento sindical sofre inúmeras derrotas, não apenas no cerceamento de sua autonomia, mas também com o assassinato de dirigentes sindicais e lideranças trabalhistas, especialmente após a promulgação do Ato Institucional no 5 em 1968, que previa a cassação de direitos políticos e civis a opositores do regime militar, a desmobilização dos movimentos sociais por meio da criminalização deles, a suspensão do habeas corpus, entre outros. Com a militarização da Justiça, especialmente após o AI-2, prisões arbitrárias, torturas sistemáticas e assassinatos de presos políticos tornaram-se cada vez mais recorrentes, ainda que oficialmente negados por uma pretensa legalidade do regime. Apesar dos

\footnotetext{
1 "A repressão aos sindicatos mostrava bem o caráter da ditadura que se instalava. A articulação de militares com empresários ligados ao grande capital nacional e estrangeiro, apoiada pelos latifundiários e políticos conservadores, deu-se em torno da contenção dos avanços dos movimentos organizados de trabalhadores no campo e na cidade. Por outro lado, a crise econômica, que só fazia crescer desde o fim do governo JK, seria combatida pela ditadura com uma receita cujo principal remédio era o arrocho salarial. Para tanto, controlar os sindicatos era fundamental" (MATTOS, 2009, p. 101).
} 
expurgos de líderes sindicais os movimentos continuaram a existir, mesmo que sob intensa repressão, esvaziando-se conforme o regime ampliava o uso da violência, especialmente após a greve geral de Osasco (SP) em 1968.

Frente à impossibilidade de manter o regime por meio da intensa exploração econômica dos trabalhadores e o uso da repressão, o governo militar apresenta o início de uma abertura política com o governo do general Ernesto Geisel (1974 1979). É neste momento que o movimento sindical reencontra a possibilidade de se reorganizar, mobilizando a luta salarial e o direito de greve. Apesar de ter como principal expoente o sindicato dos metalúrgicos no $\mathrm{ABC}$ paulista, o ressurgimento do movimento se expande a inúmeras categorias trabalhistas para além das fábricas, tendo como o ano de 1978 uma data marcante para o surgimento do novo sindicalismo com as greves no ABC paulista.

Com o ressurgimento do sindicalismo brasileiro pós-golpe de 1964, houve uma disputa interna entre setores da esquerda, cristalizados no Partido dos Trabalhadores (PT) - formado em 1980 - e no Partido Comunista Brasileiro (PCB). O primeiro se autodenominava como o "bloco combativo" e seus agrupamentos como Oposições Sindicais. Exerciam uma forte crítica à Unidade Sindical do PCB, criticando-os como "reformistas" e "corporativistas". O grupo combativo constituíase, então, principalmente pelo contraponto ao PCB e à sua política de colaboração de classes, entendida como medida populista e que dificultava o desenvolvimento da luta dos trabalhadores.

A tarefa dos sindicalistas "combativos" era, portanto, a um só tempo, criticar as posições do PCB no passado e combater suas propostas no presente.

Nesta lógica, ressaltava-se que o movimento que despontava era formado por sindicalistas "puros", trabalhadores "genuínos", a partir das lutas da base por eles organizadas. (...) Mais do que uma superação, o "novo" movimento sindical deveria ser a negação pura e simples do que o PCB realizava no presente e do que, junto ao "sindicalismo populista", havia realizado antes de 1964. A luta do presente trazia, assim, o passado como referência e instrumento na disputa" (SANTANA, 1999, p. 105).

A distinção dentro do movimento sindical foi realçada também pelos estudos acadêmicos. A possibilidade de se concretizar uma ruptura com as práticas sindicais anteriores tornava possível a crítica e a mudança real na situação dos trabalhadores. Francisco Weffort é um exemplo de acadêmico e militante que atuou tanto na construção de linhas de pesquisa acerca do "novo" sindicalismo quanto na construção do PT (ver SANTANA, 1999). Suas pesquisas apontavam para a prática populista do "velho" sindicalismo, baseado no reformismo, no controle das massas e na ligação com o Estado, afastando-se das bases e fragmentando o próprio movimento sindical, tornando-o um movimento de cúpula. Foi predominante a categorização do "sindicalismo populista" como proposta por Weffort, marcando o novo sindicalismo com um sentimento de necessidade de superação do passado, cujas práticas sindicais se compreendiam como negativas. 
Contudo, como mostrado em alguns trabalhos, a prática sindical anterior ao golpe de 64 não pode ser reduzida à relação entre a cúpula sindical e o Estado. Ruy Braga (2012) enxergará tanto no período anterior quanto no período pós-golpe, com algumas diferenças importantes, a presença de uma constante insatisfação entre a camada com condição de vida mais precária do operariado urbano - o precariado - frente às condições despóticas do capitalismo. 0 autor mostra que, através das análises de revisitas etnográficas na produção sociológica entre as décadas de 60 e 90, já no início dos anos 50, a repressão policial era amplamente utilizada para combater as greves, evidenciando uma forte associação entre o patronato e a polícia, consequentemente, com o Estado.

Apesar da existência de uma cúpula sindical atrelada ao Estado já desde a Era Vargas (1930-1945), o movimento operário mostrou-se ativo em sua base, pressionando esta mesma cúpula a lutar por ganhos para a classe operária. Os anos 50 e 60 apresentam um elevado movimento grevista, evidenciando uma participação ativa e reivindicatória desta base, contrária às teses de completa passividade e clientelismo. A experiência coletiva na construção da resistência e combatividade do jovem precariado que chegava do campo construiu uma forte solidariedade (através de laços afetivos, apoio mútuo, construção coletiva de residências) que intensificava os ciclos de greve, primeiro contra a carestia, depois, já na década de 60, com pautas mais politizadas (institucionalização de direitos, reivindicações salariais).

As greves de 68 e posteriormente aquelas que marcariam o início do novo sindicalismo estavam sendo construídas no chão de fábrica desde a década de 50 , e sem essa experiência coletiva de prática sindical combativa pela base não seria possível. Ao contrário das teses de uma prática sindical populista no período, este não criou consentimento, mas "inquietação operária" (idem, p. 53)². Inquietação que neste período ainda era inorgânica, mas que, com inúmeras experiências de paralisação, operações tartaruga e greves confluiriam para uma base mais orgânica e combativa, tornando-se um novo sujeito político em 1978.

Após a derrota da greve de Osasco (SP) em 1968, por meio de intensa repressão do Estado, a Oposição Metalúrgica de São Paulo (OSM-SP) inicia a sua formação criticando o cupulismo sindical, que fora incapaz de mobilizar os operários de setores dinâmicos, a repressão policial e o atrelamento entre Estado e patronato. Nascia, assim, a maior participação do chão de fábrica, das bases, a partir da intensificação das comissões de fábrica (SADER, 2001; BRAGA, 2012). Os operários articularam-se junto de outros movimentos sociais contestatórios, como o estudantil e associações de bairro, renovando as formas de resistência, especialmente dentro da fábrica, visto que a greve era proibida e a manifestação em local público abria espaço para a repressão policial. As pequenas lutas cotidianas (como por maior tempo de almoço, por mudanças gerais no ambiente de trabalho) foram valorizadas enquanto reivindicações e vitórias, muitas vezes conquistadas fora do sindicato, através de pressão da base, formando um sentimento de solidariedade e de ação coletiva.

\footnotetext{
2"a hegemonia populista caracterizou-se por um estado permanente de inquietação social entre os operários, especialmente sua fração precarizada" (BRAGA, 2012, p. 66). Itálico no original.
} 
Começa assim uma aproximação entre as correntes de oposição com a base que se fortalece em 1973 com mobilizações no local de trabalho pelo direito de greve e negociações coletivas, motivadas pela escassez de força de trabalho e degradação dos níveis salariais. 0 início da descompressão política em 1974 com Geisel e o confronto da burocracia sindical de São Bernardo (SP) com o governo e as empresas apresentavam um novo quadro. Em 1977, a euforia com o Milagre Econômico se enfraquecia cada vez mais e a distensão política abria espaço para o fortalecimento do movimento sindical. Naquele ano, uma coordenação política entre os operários profissionais e os metalúrgicos criou uma ampla mobilização por reposição salarial. A organização do sindicato dos metalúrgicos de São Bernardo, que já tinha a sua frente Luís Inácio Lula da Silva desde 1975, "soube se fazer portador - e soube potenciar - algumas dessas pressões, que vinham de suas bases" (SADER, 2001, p. 288). O movimento grevista de 1978 repercute nacionalmente e reconquista direitos trabalhistas na prática, e conflui em 1979 para a politização do movimento ao perceber a aliança empresarial-militar na repressão à inquietação social e percebendo também a importância da greve para as reivindicações trabalhistas ${ }^{3}$.

Ao mesmo tempo em que estimulava as diversas formas de resistência operária dentro da empresa, incluindo algumas greves, pois a própria existência do sindicato depende da mobilização e organicidade dos trabalhadores, o sindicato de São Bernardo esforçava-se em construir uma imagem confiável perante as empresas, precisando estabelecer alguns acordos que passavam por cima da pressão da base. Nas palavras de Ruy Braga, “amparada no prestígio acumulado durante o ciclo grevista, essa burocracia assegurou um tipo de consentimento operário alicerçado na regulação dos conflitos fabris sob o controle da empresa" (Ibidem, 2012, p. 178).

Temendo o risco que a ruptura com a estrutura oficial do sindicato trazia para a reprodução do poder burocrático da direção metalúrgica, esta, após a derrota da greve de 1980, reconciliou-se progressivamente com o sindicalismo de Estado, sem deixar de negociar concessões aos operários.

Luís Inácio da Silva, o Lula, então presidente do sindicato dos metalúrgicos de São Bernardo do Campo (SP), figura marcante no movimento do novo sindicalismo, afirmava que o sindicato deveria ser uma organização espontânea cuja existência ocorresse por exigência do trabalhador. Criticava, dessa forma, a existência do imposto sindical, presente desde 1940, portanto desde o Estado Novo (1937 - 1945), que atrelava o sindicato ao Ministério do Trabalho, tornando desnecessária a luta e a organização sindical ao estabelecer como obrigatória e direta a contribuição aos sindicatos, controlados pelo Estado (CARvalho, 2001; MATTos, 2009). A crítica se direcionava, portanto, ao modelo de sindicalismo atrelado ao Estado e longe das

\footnotetext{
3 "Marcadas pela espontaneidade e por sua radicalidade, tais greves inauguraram o que seria uma nova prática sindical e política. Rejeitando a colaboração, os pactos sociais e o imobilismo que, em seu entendimento, haviam caracterizado boa parte da esquerda brasileira até então, as greves do ABCD [paulista] criaram um movimento social fundado no confronto social e na independência de classe" (BrAGA e SANTANA, 2009, p. 299).
} 
suas bases populares, os próprios trabalhadores, retirando-lhes a autonomia pela luta por melhores condições de trabalho.

0 fortalecimento do movimento ocorre também devido ao esgotamento do modelo de acumulação capitalista reforçado pelo golpe: a superexploração com arrocho salarial e o aumento da dívida pública esgotaram o "milagre econômico". A reivindicação do reajuste salarial assumia, então, mais do que uma dimensão econômica, mas também política ao combater o motor do modelo de desenvolvimento econômico da ditadura: o arrocho salarial ${ }^{4}$.

O sindicalismo "autêntico", simbolizado por Lula e o ABC, já havia gerado, em aliança com outros setores sociais, em 1980, o Partido dos Trabalhadores (PT). Desde 1979, porém, grandes esforços foram feitos para aglutinar o sindicalismo combativo em torno de uma central. Esses esforços darão origem à Central Única dos Trabalhadores (CUT). Reunindo, quando de sua criação em 1983, os sindicatos identificados com as propostas do "novo sindicalismo" e as oposições sindicais que lutavam para afastar os pelegos dos sindicatos - tendo como melhor exemplo a Oposição Sindical Metalúrgica de São Paulo - a CUT esteve por trás de boa parte das ações de retomada das mobilizações sindicais no período. No Congresso Nacional das Classes Trabalhadoras que fundou a CUT, aprovaram-se os estatutos da central, que incluíam, entre outros princípios, a defesa da: democracia sindical; unidade da classe trabalhadora; liberdade e autonomia sindicais; organização por local de trabalho e, em um nível estratégico mais amplo, afirmavam, em seu artigo 2: 'A CUT é uma central unitária, classista que luta pelos objetivos imediatos e históricos dos trabalhadores, tendo a perspectiva de uma sociedade sem exploração, onde impere a democracia política, social e econômica. Seu princípio fundamental é a defesa intransigente dos direitos, reivindicações e interesses gerais e particulares dos trabalhadores brasileiros bem como do povo explorado' (CUT, I Conclat, p. 178) (MAтTos, 2009, p. 123).

Apesar das inúmeras conquistas do novo sindicalismo, principalmente no direito de se organizar e nas conquistas salariais, manteve-se a estrutura sindical corporativista: a unicidade sindical, o monopólio da representação, o poder normativo da Justiça do Trabalho e o imposto sindical (extinto apenas em 1998).

\section{Vocabulários de motivo e agência}

Frente ao questionamento da objetividade das ciências sociais, Max Weber (1904) afirmou que haveria nos humanos um preenchimento abstrato que possibilitaria a legitimação da ação social ao lhe conferir sentido. A ação social estaria marcada pela influência mútua - influencia e é influenciada por outra ação - e pela constante cobrança de sentido da ação pelos outros atores envolvidos. A própria ação é, então, sustentada pela sua motivação.

0 motivo estará dependente da aceitação dos outros atores envolvidos e dos valores mobilizados. Tais valores compõem um quadro lógico hierárquico e hierarquizante que preenche a ação de sentido conforme são mobilizados. Estes

\footnotetext{
4 "a luta pelo acesso aos ganhos da produtividade por parte das classes menos privilegiadas transforma-se necessariamente em contestação ao regime, e a luta pela manutenção da perspectiva da acumulação transformase necessariamente em repressão" (OLIVEIRA, 1972, p. 119).
} 
valores tornam-se o objeto de análise da sociologia compreensiva de Max Weber, tornando toda sociologia uma sociologia dos valores ou da moral, podendo esta ser pensada como uma gramática ou como uma capacidade cognitiva, histórica e contextualmente inseridos ${ }^{5}$.

Charles Wright Mills (1940) irá propor a análise de vocabulários de motivo, portanto uma sociologia da moral, tendo como base a sociologia compreensiva de Max Weber e o pragmatismo filosófico.

O pragmatismo filosófico surge em 1860 nos Estados Unidos da América com o Clube Metafísico, cujo objetivo era afastar a metafísica da sua filosofia. Charles Sanders Peirce foi o seu principal expoente filosófico, criticando, principalmente, o pensamento moderno cartesiano. A dúvida, para Peirce, não acontece o tempo todo, pelo contrário, é no estado de crença que os atores tendem a se dobrar sobre o mundo. Dentro dessa filosofia não haveria diferença de substância entre as coisas, as palavras e o pensamento, tudo seria signo, todo sentido estaria fixado através do uso de signos, contextualizados, socialmente negociados e produtores de efeito - de consequência.

A influência do Pragmatismo filosófico na sociologia americana permitiu pensar o ator como signo e, como tal, aberto a interpretações e atribuições sociais. Para Wright Mills (1940), os atores sociais estão inseridos socialmente por meio de observação e influência mútua de ações sociais, sob uma lógica e uma gramática moral de motivos que funcionam como se fossem uma língua, dando sustentação à ação. Motivos e ações são negociados e aceitos em determinadas situações, de forma que Wright Mills toma como seu objeto de análise a explicação de motivos e a interpretação de condutas pelos atores sociais.

Se os atores sociais agem constantemente em estado de crença, a conduta social só será questionada por outros atores quando for frustrada ou insatisfatória na sua justificação. Verbalizar a ação torna-se tão importante quanto a ação em si, tornando-a uma nova ação, que influencia e é influenciada, delimitada pelo vocabulário moral do ator, que delimita a interpretação das ações e discursos, suas e de outros atores.

Seguindo a proposição de historicizar os vocabulários de motivo, Harold Garfinkel (1967) irá propor o estudo das práticas cotidianas como fenômeno em si, compreendendo que as práticas para realizar uma ação de forma organizada e coesa são idênticas às práticas para relatá-las. Garfinkel propõe a etnometodologia em um período em que as ciências sociais começavam a questionar o funcionalestruturalismo de Talcott Parsons (Heritage, 1987). Através da influência da fenomenologia de Schütz, Garfinkel criticou a teorização de Parsons e a redução do ator nesta teoria, reduzindo-o frente à coesão social e à ação motivada para manter

\footnotetext{
5 "A validade objectiva de todo o saber empírico baseia-se única e exclusivamente no facto de a realidade dada se ordenar segundo categorias subjectivas, no sentido específico de constituírem a pressuposição do nosso conhecimento e de se ligarem à pressuposição do valor da verdade que só o saber empírico nos pode proporcionar" (WEBER, 1904, p. 108. Grifos no original).
} 
a ordem e o consenso. Para Garfinkel e Schütz o mundo é interpretado à luz de categorias e constructos do senso comum, sendo sociais na sua origem. Os atores, portanto, possuem um vocabulário e uma explicação para as suas ações baseado num estoque de experiências prévias e na tipificação de certas ações. Uma situação fora do comum, portanto, causaria perturbação e seria compreendida pelos atores como uma "ameaça à ordem normativa dos acontecimentos" (Idem, p. 337). Tornase preciso, então, analisar a forma e o processo pelo qual a ação traz o seu próprio sentido, contextualizando-a ${ }^{6}$.

A ação social para Garfinkel deve ser compreendida pela mútuainteligibilidade e pela responsabilidade moral da ação, produzida pelo agente, devendo ser considerado as expectativas sobre as ações: de manutenção ou de desvio das expectativas constitutivas da ação, baseadas em uma experiência prévia da norma. Frente a uma ação fora da norma tenta-se enquadrá-la em alguma outra norma. Quando não se consegue atribuir sentido a ela surgem a dúvida e o desconforto, atribuindo a tal ação negatividade e condenação moral na sua motivação.

Todo ator tem consciência da norma e, portanto responsabilidade na ação, devendo o desvio ser analisado no seu contexto de elaboração como um sentido da ação. Mais importante do que compreender a ação padronizada é compreender a importância do contexto, sempre em transformação pela ação, e a explicação, que também é ação. A normalidade percebida deve ser compreendida como pressuposto metodológico da etnometodologia, para a qual as práticas se definem, admitindo a expectativa normalizadora como aspecto irremediável da operação, mesmo que não padronizada, em busca da expectativa do próprio ator e de outros envolvidos (Heritage, 1987).

\section{A prática da crítica}

Utilizando a etnometodologia, Marvin Scott e Stanford Lyman (1968) se dobram sobre o que eles consideram a questão fundamental da sociologia: como a sociedade é possível. Pretendem analisar a fala, compreendendo-a como o ritual mais sutil para a manutenção das associações. Os autores se propõem a compreender o account (prestação de conta). 0 account surge como uma indagação valorativa de uma ação, de forma a evitar conflitos. São situados de acordo com os status dos atores e padronizados conforme a cultura em que se inserem - sem perder de vista a contextualização - de modo que certos accounts são esperados quando se extrapola uma expectativa, estando estabilizados em uma determinada terminologia. A prestação de conta pretende explicar um comportamento tomado como indevido e imprevisto.

A vida social é operacionalizada cotidianamente por discursos de prestações de contas e de manutenção da ordem. 0 account pode ser acatado, restabelecendo

\footnotetext{
6 "O fenômeno [normal] consiste, também, na analizabilidade de ações-em-contexto, dado que não só não existe um contexto-em-geral, mas também todo uso de "contexto" é por si, sem exceção, essencialmente indexical" (GARFINKEL, 1967, p. 117).
} 
o equilíbrio do relacionamento, ou não, dependendo das expectativas prévias ${ }^{7}$. É possível pensar o surgimento das críticas propostas pelo novo sindicalismo como uma cobrança de account das relações sindicais até então estabelecidas e das relações trabalhistas promovidas pelo governo, sindicatos e patronatos. 0 ator social agirá conforme um senso de julgamento, considerado como uma capacidade moral e cognitiva de julgar e criticar a mobilização de explicações e vocabulários morais. Os atores, portanto, cobram o sentido da ação dos outros (SCOTT e LYMAN, 1968).

É com o pragmatismo francês que a moralidade é assumida como faculdade cognitiva, como capacidade moral dos atores de aprovar ou reprovar algo em curso, estabelecendo-os como sinônimos socialmente construídos de bem e mal, qualificando o que se aprova ou desaprova. A vida social é constituída como uma disputa negociada pelos valores mobilizados nas ações e explicações dos atores.

A sociologia da moral, ou sociologia da crítica, francesa surge como crítica à hegemonia do modelo de dominação da sociologia crítica de Pierre Bourdieu. A sociologia de Bourdieu (1972) compreende as práticas interacionais como operação inserida na agência dos atores sociais, compreendendo que estes agem como se existisse um poder superior (a estrutura) que rege a agência. A agência é construída, mas delineada pela dominação, resultado da dominação de classe, cristalizando no habitus as capacidades de ação conforme as posições presente e passada na estrutura social. 0 pragmatismo francês irá, contudo, compreender que os agentes mobilizados pela sociologia crítica de Bourdieu não estão constantemente satisfeitos com a forma como estão sendo classificados, devido à perda de força do agente, constantemente dominado, na maior parte das vezes sem o saber.

Luc Boltanski e Laurent Thévenot (1999) mostraram que os atores, ao operarem a classificação, qualificam e hierarquizam as suas posições. A disputa nasce desse primeiro passo, tendo posteriormente a exigência de sentido, a apresentação de provas (justificação) e a mobilização da Justiça, aceitando a classificação ou não. A proposta principal é um retorno à etnometodologia: os atores se manifestam criticamente à categorização; os atores têm capacidade crítica. Os autores propõem, então, uma sociologia da crítica: a crítica é possível a todos os atores, ainda que não ocorra o tempo todo, por ser um estado de ruptura dentro do contínuo do hábito.

0 momento crítico é raro e deve ser compreendido na sua particularidade temporal: é situacional, portanto. A crítica coloca em questão que algo está sendo afirmado como universal ou que algo injusto está em curso de ação. A crítica é então mobilizada por atores que estão imersos em uma situação construída pelos próprios atores. Estes ocupam estados temporais e hierárquicos, mas não intrínsecos. Este estado é chamado pelos autores de grandeza, compreendendo a vida social como uma disputa por essas grandezas (posição situacional de diferenciação) escassas e pelas explicações dessas grandezas (que ocorre no momento da crítica; tensão de grandezas).

\footnotetext{
7 Ações taken-for-granted, tidas como garantidas e por isso até então inquestionáveis, possibilitando a manutenção das relações sociais.
} 
A grandeza dos atores envolvidos estará dependente da situação em que ele se encontra no momento da crítica, que é o momento de percepção de uma diferença de grandeza que é tomada como injusta. Questionar o estado de grandeza do outro é questionar a sustentabilidade da legitimidade dos valores que mantém aquela grandeza criticada. Os atores, contudo, são dotados de potência para o acordo e a ação crítica tende a restabelecer a manutenção da rotina quando a equivalência das posições de grandeza é restabelecida como justa, operacionalizando o princípio de bem comum (BolTANSKI e THÉvENOT, 1999) para os atores envolvidos no conflito.

During the course of a dispute, the reference to a principle of equivalence is also a basic operation necessarily implemented in order to set up a claim, unveil an injustice and ask for an atonement. In order to keep violence away from the situation, the discontented person must display his motives by associating them with proofs and justifications and in such a way that they can be redressed (Idem, p. 363).

O modelo de Boltanski (2000) se propõe a analisar a denúncia pública, ou quando uma crítica individual se torna pública, tornando públicos o descontentamento e a mobilização dos valores criticados e propostos. Nesse sentido, a crítica exercida pelo novo sindicalismo pode ser compreendida como uma denúncia tornada pública ao mobilizar o descontentamento de diversos segmentos de trabalhadores, fossem frente às relações entre o "velho" sindicalismo e o governo militar ou às relações do governo com o patronato, coibindo as greves e mantendo o arrocho salarial. 0 sistema actancial do modelo permite compreender os sindicatos como atores sociais pela sua capacidade de influir nas relações sociais, ou seja, de ter influência e maior importância, ainda que todos os atores envolvidos exerçam a sua agência8.

A crítica (BoLTANSKI, 2000) tem como pressuposto a multilateralidade das posições relativas dos actantes no momento da crítica, tensionando as posições de grandeza. São quatro as posições típicas, e dessa forma quatro actantes ${ }^{9}:$ o que denuncia (denunciante), o que é a favor da denúncia (vítima), o objeto da denúncia (acusado/perseguidor) e a pessoa para quem se faz a denúncia (juiz). A denúncia é a expressão da negatividade da situação crítica, apresentando como injusta uma diferenciação de grandeza, e apresenta um caráter de disputa: é uma operação de conquista por apresentação de provas; a denúncia é, também em si, uma prestação de contas.

Ao propor uma ruptura interna na história do movimento sindical, os atores do novo sindicalismo mobilizam estratégias capazes de qualificar a sua argumentação e estabelecer novos estados de grandeza. Uma delas é o uso do "novo" como forma de distinção do modelo por eles propostos, deixando claro que aquela nova forma de

\footnotetext{
8 "It is precisely because persons, unlike things, can exist in a plurality of worlds that they always have the possibility of denouncing a situation as unjust (even if criticism is unequally easy according to the current constraints they have to deal with)" (BoLTANSKI e THÉVENOT, 1999, p. 373).

9 "En nuestras sociedades todos los actores disponem, en efecto, de capacidades críticas, y pueden movilizar, aunque sin duda de manera desigual según la situación, recursos críticos que ponen en práctica en el curso de sus actividades cotidianas. En ese sentido, estas sociedades pueden ser calificadas como sociedades críticas" (BoLTANSKI, 2000, p. 260).
} 
sindicalismo é radicalmente diferente da praticada anteriormente. Lula, ao comentar a evolução do movimento sindical diz que "teríamos de fazer uma certa divisão do movimento sindical [entre] antes e após 64. [...] eu acredito que o movimento sindical antes de 64 foi muito usado politicamente, fazia-se talvez uma politicalha, em vez de defender realmente a categoria" (SANTANA, 1999, p. 107).

Ao dizer também que "muitos movimentos eram feitos por interesses políticos, muitas vezes em benefício de quem estava no poder e mesmo de quem não estava mas queria chegar lá" (idem, p. 107) Lula desqualifica o movimento sindical anterior ao diminuir a alteridade dos seus participantes, revelando associação com interesses obscuros (BolTANSKI, 2000). Nesse caso, a desqualificação ocorre pela existência de um interesse político que, relacionado a um Estado cuja principal medida econômica era o arrocho salarial, estaria em desacordo com as propostas de um sindicato, que deveria lutar pela melhoria do salário, pela liberdade de associação e de greve e segurança trabalhista. Nas palavras de Lula:

\footnotetext{
"A estrutura sindical brasileira (...) é totalmente inadequada. Não se adapta à realidade, foi feita de cima para baixo (...). É preciso acabar com a contribuição sindical que atrela o sindicato ao Estado. A estrutura e a legislação sindical deveriam ser reformuladas como resultado das necessidades. 0 sindicato ideal é aquele que surge espontaneamente, que existe porque o trabalhador exige que ele exista" (MATTos, 2009, p. 119).
}

Lula chega a autodenominar este novo sindicalismo de "autêntico", aludindo para a inautenticidade do antigo modelo de sindicalismo por se afastar dos interesses dos trabalhadores. Aliando estas críticas à presença de intelectuais, de acadêmicos, de membros eclesiásticos e de lideranças populares, o novo sindicalismo, que se construiu sob a dupla actância de denunciante e vítima (ainda que nesta haja um sem número de trabalhadores não filiados aos sindicatos), engrandeceu-se frente à opinião pública, consolidando maior autoridade ao novo sindicato e à crítica feita.

O movimento sindical pretendia, portanto, exercer uma crítica também ao modelo capitalista utilizado pelo regime militar; um modelo de superexploração do trabalhador e, consequentemente, de altos lucros aos empregadores. Tais críticas são apropriadas pelo capitalismo, possibilitando a sua continuação. Por ser insaciável, o capitalismo, nas suas figuras do patronato e do Estado, precisa compreender as provas mobilizadas pelas críticas sindicais, institucionalizando-as e diminuindo a percepção da diferença de grandeza.

Como [o capitalismo] não pode encontrar fundamento moral na lógica do processo insaciável de acumulação (por si só imoral), o capitalismo precisa extrair de ordens de justificação que lhe são exteriores (aqui chamadas cidades) os princípios de legitimação que lhe faltam (BolTANSKI e CHIAPELlo, 1999, p. 484. Itálico no original). 
O capitalismo, que "também está condenado a reconhecer a função do clamor (voice)" (idem, p. 489), se serve da crítica cuja energia é obtida na indignação, no caso dos trabalhadores mobilizados pelo novo sindicalismo brasileiro a indignação de ter um salário que não era o suficiente para os gastos básicos do mês, frente a um regime de alta exploração, de hiperinflação, de violência e arbitrariedade policial e do Estado e da precariedade dos serviços públicos. A crítica evidencia a relação salário-lucro, mobilizando argumentos de ambos os lados (a exploração versus a impossibilidade econômica da empresa de viabilizar aumentos salariais), estabelecendo um conflito de vocabulários morais, revelando aquilo que transgride a justiça, sendo possível continuar o conflito em um período no qual o funcionamento democrático do debate político e social começava a se expandir, ainda que de forma lenta e limitada.

O novo sindicalismo se insere no que Boltanski e Chiapello (1999) consideram como crítica ao novo capitalismo dos anos 1970, ocorrendo não mais por vias do Estado, visto que este fora acoplado pelo capitalismo ${ }^{10}$. Exercia, dessa forma, uma crítica radical ao contestar os princípios de equivalência e a disparidade entre trabalhador e empregador através da relação salário-lucro, acusando também o Estado liberal. A crise da dívida externa, a hiperinflação e os gastos públicos foram estratégias do capitalismo (devendo ser entendido sempre na sua materialização em economistas, jornalistas, analistas sociais, trabalhadores, sindicatos, colunas de opinião, etc.) de deslocamento da crítica, apresentando justificativas para a contraprova no âmbito contábil, possibilitando a retomada do impulso de acumulação ou, ao menos, frear os avanços trabalhistas.

\section{Conclusão}

Se o capitalismo se vale das críticas para manter a acumulação, este precisa formular um novo espírito e nele encerrar as exigências de justiça e com base nas ordens de justificação gerais. Tais ordens são chamadas por Boltanski (2000; com ThÉvenot, 1999; com ChIAPPElo, 1999) como cidades (cités), cujas existências são históricas e, portanto, situadas no tempo e no espaço, evidenciando uma metafísica política e enraizada em dispositivos, objetos e direitos que explicitem a ideia de justiça e de bem comum.

A formação de uma cidade é um regime de categorização e operacionaliza a justificação e a crítica, impondo limites à grandeza. 0 novo sindicalismo ("autêntico") estabelece por meio da crítica ao velho sindicalismo ("corporativista") uma crítica aos valores estabelecidos desde o governo de Juscelino Kubitschek e intensificados pelo regime burguês-militar. Através de inúmeras estratégias de engrandecimento, algumas aqui analisadas, o novo movimento sindical possibilitou o seu crescimento

\footnotetext{
10 “Ora, o capitalismo nunca pôde e ainda hoje não pode sobreviver sem o apoio do Estado. É o poder político que garante, por exemplo, respeito aos direitos de propriedade; é o Estado que dispõe dos meios de coerção capazes de impor respeito aos direitos reconhecidos dos trabalhadores, mas também aos interesses das empresas e aos contratos por ela firmados" (BolTANSKI e CHIAPELlo, 1999, p. 511).
} 
no debate público e nos acordos com o patronato e com o governo, conquistando algumas melhorias reais na condição do trabalhador.

Na década de 90, o novo sindicalismo foi alvo de inúmeras autocríticas e renovação das análises acadêmicas e práticas militantes. 0 surgimento de novos trabalhos que apontavam para a inexistência de uma total ruptura do movimento sindical na década de 70 e iam contra a total negativação do sindicalismo praticado anteriormente, possibilitaram a renovação do debate acadêmico e das próprias práticas sindicais (SANTANA, 1999). A própria prática sindical da Central Única dos Trabalhadores (CUT), criada em 1983 num esforço do novo sindicalismo, modificouse nos anos 90, assumindo um caráter de negociação e harmonia entre a classe trabalhadora e empresarial, assinando acordos que diminuíam a capacidade de resposta dos trabalhadores, que consolidavam diminuições diretas e indiretas do salário, e muitas vezes com incentivos às políticas de demissão. Assumia-se, nos anos 90, a posição corporativista tão criticada nos anos 70 e 80 sob o discurso de manter empregos, quando a experiência foi a de contínua perda de postos de trabalhos; e, nos anos 2000 assumia-se uma relação de harmonia com o governo PT, cujo presidente era o Lula (MATTOS, 2009).

Conforme Eder Sader, "quando falamos da identidade de um movimento social, estamos nos referindo a uma identidade polêmica, produzida no tempo através de ações muitas vezes contraditórias, com significados ambíguos, muitas vezes desfeita e refeita através de atos que estabelecem novas vias de continuidade e levam a reinterpretações do passado" (2001, p. 228). A atribuição de sentido de qualquer movimento social será dada de forma tensa e mobilizará argumentos e atores de forma a elevar a sua grandeza dentro da situação social. A construção da identidade de um movimento social como o novo sindicalismo se torna essencial, especialmente, em um período marcado pela política repressiva a este segmento social, sendo de extrema importância noções como autonomia e diversidade. Tornavam-se, conforme os ganhos políticos frente ao regime, verdadeiros sujeitos políticos, com extrema importância no quadro de distensão e redemocratização políticas. A tensão presente na significação dos movimentos sociais também é feita pelos seus atores, como no caso da apropriação do "novo" pela prática sindical construída ao longo da década de 70 .

A tese da inquietação operária de Ruy Braga evidencia a forte capacidade das classes trabalhadoras, em especial as de posições inferiores na hierarquia social e na divisão do trabalho. Inquietação esta que se confronta com a então incapacidade do governo ditatorial de manter o discurso de crescimento econômico ao longo dos anos 70. 0 período de distensão política influencia e torna possível a constituição dos sindicatos sob aquela que parecia ser a sua maior herança e prática: a política de chão de fábrica: "a precária inserção no mundo urbano associada à transparência da exploração econômica estimulou comportamentos críticos por parte dos operários fordistas, em especial os setores não qualificados e semiqualificados na cidade de São Paulo, que rapidamente engajaram-se em um ciclo de greves gerais" (BRAGA, 2012, p. 53). 
As críticas foram importantes para terminar de esgotar o modelo adotado pela ditadura, contudo não exerceram uma mudança radical nas práticas governamentais frente à relação salário-lucro (ou capital-trabalho, conforme uma linguagem marxista). A conclusão final a que se chega é que, apesar do esforço do novo sindicalismo brasileiro nas décadas de 70 e 80 do século XX, o capitalismo soube mobilizar e se apropriar melhor destas críticas e das formações de novas cidades, apropriando-se tanto de líderes sindicais como aprofundando a sua relação com o Estado, mantendo as altas taxas de lucratividade, a unicidade sindical (dificultando a pluralização das críticas) e a flexibilização da jornada de trabalho. Contudo, é apenas

na hipótese da constituição e do enraizamento em dispositivos duráveis de um novo espírito do capitalismo, o realismo dessa formação ideológica e sua capacidade mobilizadora dependerão em grande parte da pertinência e da intensidade das pressões que a crítica souber exercer sobre a ordem ou - para sermos mais exatos - sobre a desordem que caracteriza as formas atuais da acumulação capitalista (BoLTANSKI e ChiAPELLo, 2009, p. 523).

É, portanto, apenas pela continuação da crítica e a mobilização de novas e velhas cidades que se torna possível a modificação e a denúncia de injustiças e diferenças de grandeza, apresentando provas e exigindo justificativas (accounts - ScoTT e LYMAN, 1968) ao mesmo tempo em que se deve estar atento aos deslocamentos mobilizados pelos discursos de crise e de inviabilidade contábil do capitalismo.

\section{Referências bibliográficas}

Boltanski, L. (2000). El amor y la justicia como competencias: Tres ensayos de sociología de la acción. Buenos Aires, Amorrotu.

Boltanski, L. e Chiapello, É. (2009). O novo espírito do Capitalismo [1999]. São Paulo, Martins Fontes.

Boltanski, L. e ThÉvenot, L. (1999). “The Sociology of Critical Capacity”. European Journal of Social Theory, Vol. 2, p. 359-377.

Bourdieu, P. (2003). "Esboço de uma teoria da prática” [1972]. In: ORTIZ, R. (org). A sociologia de Pierre Bourdieu. São Paulo, Olho d’Água, p. 39-72.

Braga, R. (2012). A política do precariado: do populismo à hegemonia lulista. São Paulo, Boitempo Editorial.

Braga, R. e Santana, M. A. (2009). "O pêndulo oscilante. Sociologia do trabalho e movimento sindical no Brasil". Braga, R. e SAntanA, M. A. (orgs.). Caderno CRH Dossiê sociologia pública v. 22, n. 56, ago.

Carvalho, J. M. de. (2001). Cidadania no Brasil: o longo caminho. Rio de Janeiro, Civilização Brasileira, [2013, 16 edição]. 
Garfinkel, H. (2009). “O que é etnometodologia?”. Teoria e Cultura, Juiz de Fora, vol. 4, no 1 e 2, pp. 111-134. Disponível em:

http://www.editoraufjf.com.br/revista/index.php/TeoriaeCultura/article/ view/2035/1472>. Acessado em: 30/07/2013.

Heritage, J. C. (1996). "Etnometodologia”. In: Teoria Social Hoje. Giddens, Anthony e TURnER, Jonathan (orgs.). São Paulo, Unesp, [1987], (p. 321 - 392).

MEndonçA, S. R. de (2002). Estado e Economia no Brasil: Opções de desenvolvimento. São Paulo, Editora GRAAL, 3a edição.

Mattos, M. B. (2009). Trabalhadores e Sindicatos no Brasil. São Paulo, Editora Expressão Popular.

Oliveira, F. de. (2003). Crítica à razão dualista/O ornitorrinco. São Paulo, Boitempo Editorial.

Pogrebinschi, T. (2005). Pragmatismo: Teoria Social e Política. Rio de Janeiro, Relume Dumará.

SAntana, M. A. "Entre a ruptura e a continuidade: visões da história do movimento sindical brasileiro". Revista Brasileira de Ciências Sociais, Rio de Janeiro, Vol. 14, no 41, Outubro/99, pp. 103-120. Disponível em: <http://www.scielo.br/pdf/rbcsoc/ v14n41/1754>. Acessado em: 29/07/2013.

SADER, E. (2001). Quando novos personagens entraram em cena: experiências e lutas dos trabalhadores da grande São Paulo 1970-1980. 4.ed. São Paulo, Paz e Terra.

Scott, M. B. e Lymann, S. M. (2009). “Accounts” [1968]. Dilemas, Rio de Janeiro, vol. 2, n. 2, p. 139-172.

Weber, M. (1979). "A objectividade do conhecimento nas ciências e na política sociais" [1904]. In: Sobre a teoria das ciências sociais, Lisboa, Editorial Presença, p. 07-111.

WeFFoRT, F. C. (1977). "O populismo na política brasileira”. In: Brasil: Tempos Modernos. Org.: FURTADO, C. Rio de Janeiro, Paz e Terra, [2 ${ }^{\underline{a}}$ edição].

Wright Mills, C. (1940). Situated Actions and Vocabularies of Motive. American Sociological Review, vol. 5, n. 6, p. 904-913.

Recebido em agosto/2013

Aprovado em maio/2014 